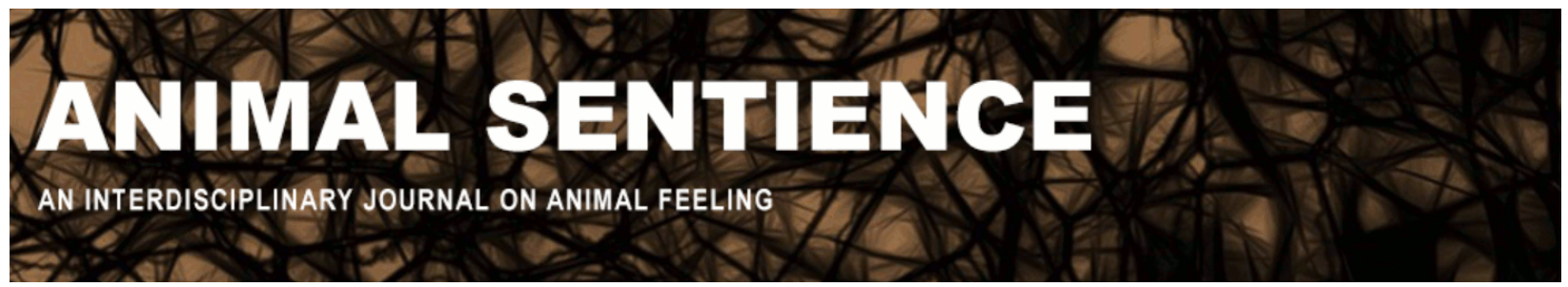

Piotti, Patrizia (2017) Positive emotions and quality of life in dogs. Animal Sentience 14(17)

DOI: $10.51291 / 2377-7478.1281$

Date of submission: 2017-12-22

Date of acceptance: 2018-01-03

(c)

This article has appeared in the journal Animal

Sentience, a peer-reviewed journal on animal

cognition and feeling. It has been made open access,

free for all, by WellBeing International and deposited

in the WBI Studies Repository. For more information,

please contact

wbisr-info@wellbeingintl.org.

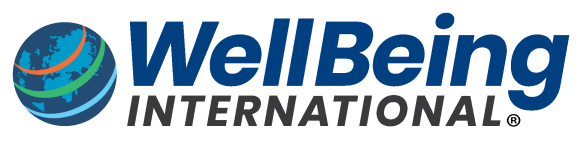

SOLUTIONS FOR PEOPLE, ANIMALS AND ENVIRONMENT 


\title{
Positive emotions and quality of life in dogs
}

Commentary on Kujala on Canine Emotions

\author{
Patrizia Piotti \\ Department of Ethology \\ Eötvös Loránd University, Budapest, Hungary
}

\begin{abstract}
Positive affect is fundamental to ensuring good animal welfare. Discrete and dimensional theories of emotion have recently been used to explore the relation between cognition and affect and to develop cognitive measures of positive affect. Human quality-of-life assessment focuses on positive affect, which is difficult to measure objectively in dogs. Expanding on Kujala's (2017) discussion of positive emotions and cognitive measures of affect, I suggest how these are relevant to assessing canine quality of life.
\end{abstract}

Keywords: dogs, emotions, cognitive measures, quality of life, dimensional theories

Patrizia Piotti, post-doctoral researcher in veterinary
behavioural medicine and comparative cognitive
neuroscience, currently studies cognitive ageing in dogs with
the Senior Family Dog Project, Eötvös Loránd University.
Patrizia's other research interests are canine collaborative
behaviour, individual differences in nonhuman animals and
humans, and psychoneuroendocrinology.
patriziapiottivet.wordpress.com

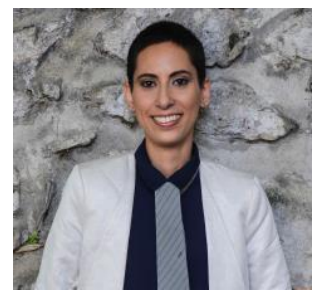

\section{Positive emotions and quality of life}

Kujala's (2017) target article touches several aspects of the study of emotion in dogs, focusing on 'discrete' (specific) emotional states, but little attention is given to the 'dimensional' approach in emotion research (Carver, 2001; Gray, 1994; Mendl, Burman, \& Paul, 2010b; Russell, 2003). Kujala does mention a bias in research outputs toward negative (unpleasant) rather than positive (pleasant) emotions. This exists despite the fact that having positive affective states is fundamental in ensuring good animal welfare (Balcombe, 2009; Boissy et al., 2007; Mendl, Burman, Parker, \& Paul, 2009; Yeates \& Main, 2008). Missing from the target article are dimensional approaches and the relevance of cognitive measures of positive affective states in assessing quality of life (QoL) for dogs.

Animals are motivated to avoid pain and suffering as well as to seek rewarding stimuli. It has been suggested that pleasure has adaptive value, encouraging them to behave in ways that favour the continuation of the species, just as avoidance of suffering does (Boissy et al., 2007). Thus, sparing captive animals from negative experiences does not ensure good welfare; providing positive experiences is also necessary (Fraser, Weary, Pajor, \& Milligan, 1997; Yeates \& Main, 2008). In fact, the absence of signs of positive affect may itself be an indication of emotional discomfort. This is particularly important in those contexts where the quality of the life of an animal is at risk (McMillan, 2003; Morton, 2007; Yeates \& Main, 2009). 
In human medicine, QoL assessment is a fundamental component of decision-making (Sanders, Egger, Donovan, Tallon, \& Frankel, 1998), whereas in veterinary medicine it is a relatively recent field (Yeates \& Main, 2009). QoL assessment should inform decision-making concerning chronic and/or painful conditions, euthanasia (McMillan, 2003), and behavioural problems (Karagiannis, Burman, \& Mills, 2015; Mills, 2017). It also allows issues to be identified that are not typically perceived by pet owners (e.g., obesity, exercise, geriatric concerns).

QoL assessment in humans emphasizes affective states, such as happiness (Schwartz \& Rapkin, 2004). Given animals' drive to seek pleasure (Boissy et al., 2006), positive affective states are directly relevant from the individual's point of view (Yeates \& Main, 2008). This is just as important for dogs (Fraser et al., 1997; Wallis et al., 2017; Yeates \& Main, 2009), although, as Kujala, Somppi, Jokela, Vainio, and Parkkonen (2017) note, assessment is problematic because the human interpretation of canine emotions is filtered by personality traits, interpersonal reactivity, and individual experiences. For this reason, objectivity and avoiding the risk of overinterpretation are especially important.

\section{An integrative approach to the study of emotion}

Mendl et al. (2010b) have proposed a psychobiological framework which integrates dimensional and discrete theories. Emotions are conceptualized on the basis of universal core characteristics: valence (positive or negative) and arousal (low or high). Valence and intensity are orthogonal, so they are mapped in a two-dimensional system: the 'core affect space', which has a bi-directional relationship with discrete emotions (Mendl et al., 2010b). Thus, the discrete approach (which is largely followed by Kujala et al., 2017) and the dimensional approach are easily integrated. Cumulative experiences of location in a core affect space have a long-term effect on the animal, such as changes in mood (Ekman, 1994). Moods are long-term, relatively stable, affective states (Davidson, 1994) related to previous experiences with the presence or probability of rewards or threats to the animal's ability to cope. An advantage of dimensional approaches is their functional relevance: they allow one to make a priori predictions of phenotypic manifestations of emotions and to define hypothesis-based measures that are universal across species, thereby facilitating translational approaches. The integrative framework proposed by Mendl et al. also takes into account both the valence of stimuli and the individual's susceptibility to them.

\section{Cognitive measures of emotions to monitor quality of life}

Another advantage of the dimensional approach is the link between cognition and emotion: cognitive measures can be used to get objective measures of emotional valence, including measures of positive emotions (Paul, Harding, \& Mendl, 2005). Kujala cites the cognitive bias tests, which measure behavioural responses to stimuli that are positive (pleasant), negative (unpleasant), or ambiguous (i.e., can be interpreted as either positive or negative). The rationale is that individuals feeling negative affect interpret ambiguous stimuli more negatively than those feeling positive affect, a phenomenon called cognitive (judgment) bias (Harding, Paul, \& Mendl, 2004). There is evidence that dogs affected by certain behavioural problems (Mendl et al., 2010a) or neuroanatomical malformations (Cockburn et al., 2017) have a relatively negative bias when judging ambiguous stimuli, compared to unaffected individuals. Behavioural and 
pharmacological treatment of separation-related problems leads to a shift towards a less negative bias in dogs (Karagiannis et al., 2015). Increased positive bias was also observed in dogs following the administration of oxytocin, especially when a communicative component was added to the test (Kis, Hernádi, Kanizsár, Gácsi, \& Topál, 2015).

These examples show how cognitive methods can be used in veterinary practice to monitor changes in long-term affective states when treating behavioural problems or managing chronic and potentially painful conditions. According to the psychobiological approach of veterinary behavioural medicine (Mills, Dube, \& Zulch, 2012; Mills \& Ewbank, 2016), an intervention for behavioural problems should be evaluated in terms of improvement of both the clinical signs and psychological state (Karagiannis et al., 2015; Mills, 2017). This should be extended to all situations where dogs' QoL is at risk (Fraser et al., 1997; McMillan, 2003; Morton, 2007). Clinical decisions regarding medical interventions, chronic conditions, geriatric patients, or euthanasia, should be based on clinical signs and affective states (Wallis et al., 2017). Similarly, clinical assessment should include measures of both negative and positive affect (Yeates \& Main, 2008).

\section{Limitations and future research}

There are limitations to the use of cognitive measures to assess emotions, such as carry-over effects (Mendl et al., 2009) and affective contrast (Burman et al., 2011). Some animals (e.g., non-ambulatory ones) may be unable to participate in certain tests. Dimensional approaches allow cognitive measures to be combined with other tools, such as infrared thermography (Travain et al., 2015, 2016) or touch-screen technologies (Wallis et al., 2017). Particularly relevant to chronically/terminally ill and geriatric animals is the question of the degree of positive affect that should be guaranteed. Future research on affective states in QoL assessment should aim to answer questions like this. Through integrated and dimensional approaches, cognitive measures can help identify behavioural phenotypes for positive and negative affect (Mendl et al., 2010b). They can also be combined with other methods - for example, hair cortisol (Esarcova, Ottferova, Kurkova, Eskova, \& Mecova, 2017), salivary IgA (Kikkawa, Uchida, Suwa, \& Taguchi, 2005), and fMRI (Andics, Gácsi, Faragó, Kis, \& Miklósi, 2014; Andics, Gál, Vicsi, Rudas, \& Vidnyánszky, 2013; Maddock, Garrett, \& Buonocore, 2003) - to develop and validate markers of both negative and positive emotional states (Paul et al., 2005).

\section{Acknowledgments}

This work has received funding from the European Research Council (ERC) under the European Union's Horizon 2020 research and innovation programme (Grant Agreement No. 680040). 


\section{References}

Andics, A., Gácsi, M., Faragó, T., Kis, A., \& Miklósi, A. (2014). Voice-sensitive regions in the dog and human brain are revealed by comparative fMRI. Current Biology, 24(5), 574-578. http://doi.org/10.1016/j.cub.2014.01.058

Andics, A., Gál, V., Vicsi, K., Rudas, G., \& Vidnyánszky, Z. (2013). FMRI repetition suppression for voices is modulated by stimulus expectations. Neurolmage, 69, 277-283. http://doi.org/10.1016/j.neuroimage.2012.12.033

Balcombe, J. (2009). Animal pleasure and its moral significance. Applied Animal Behaviour Science, 118(3-4), 208-216. http://doi.org/10.1016/j.applanim.2009.02.012

Boissy, A., Manteuffel, G., Jensen, M. B., Moe, R. O., Spruijt, B., Keeling, L. J., Winckler, C., Forkman, B., Dimitrov, I., Langbein, J., Bakken, M., Veissier, I., \& Aubert, A. (2007). Assessment of positive emotions in animals to improve their welfare. Physiology and Behavior, 92(3), 375-397. http://doi.org/10.1016/j.physbeh.2007.02.003

Burman, O., McGowan, R., Mendl, M., Norling, Y., Paul, E., Rehn, T., \& Keeling, L. (2011). Using judgement bias to measure positive affective state in dogs. Applied Animal Behaviour Science, 132(3-4), 160-168. http://doi.org/10.1016/j.applanim.2011.04.001

Carver, C. S. (2001). Affect and the functional bases of behavior: On the dimentional structure of affective experience. Personality and Social Psychology Review, 5(4), 345-356. http://doi.org/10.1207/S15327957PSPR0504

Cockburn, A., Smith, M., Rusbridge, C., Fowler, C., Paul, E. S., Murrell, J. C., Blackwell, E. J., Casey, R. A., Whay, H. R., \& Mendl, M. (2017). Evidence of negative affective state in Cavalier King Charles Spaniels with syringomyelia. Applied Animal Behaviour Science, August. http://doi.org/10.1016/j.applanim.2017.12.008

Davidson, R. J. (1994). On emotion, mood, and other affective constructs. In P. Ekman \& R. J. Davidson (Eds.), How are emotions distinguished from moods, temperament, and other related affective constructs? (pp. 49-55). New York: Oxford University Press Inc.

Ekman, P. (1994). Moods, emotions, and traits. In P. Ekman \& R. J. Davidson (Eds.), How are emotions distinguished from moods, temperament, and other related affective constructs? (pp. 56-58). New York: Oxford University Press Inc.

Esarcova, L. M., Ottferova, J. K., Kurkova, L. S., Eskova, L. L., \& Mecova, N. K. (2017). Analysis of cortisol in dog hair - a potential biomarker of chronic stress: A review, 2017(8), 363-376. http://doi.org/10.17221/19/2017-VETMED

Fraser, D., Weary, D., Pajor, E. A., \& Milligan, B. N. (1997). A scientific concept of animal welfare that reflects ethical concerns. Animal Welfare, 6(2), 187-205.

Gray, J. A. (1994). Three fundamental emotion systems. In P. Ekman \& R. J. Davidson (Eds.), The nature of emotion (pp. 243-247). New York: Oxford University Press Inc.

Harding, E. J., Paul, E. S., \& Mendl, M. T. (2004). Cognitive bias and affective state. Nature, 427(January), 312. http://doi.org/10.1038/427312a

Karagiannis, C. I., Burman, O. H., \& Mills, D. S. (2015). Dogs with separation-related problems show a "less pessimistic" cognitive bias during treatment with fluoxetine (Reconcile ${ }^{T M}$ ) and a behaviour modification plan. BMC Veterinary Research, 11(1), 80.

http://doi.org/10.1186/s12917-015-0373-1

Kikkawa, A., Uchida, Y., Suwa, Y., \& Taguchi, K. (2005). A novel method for estimating the 
adaptive ability of guide dogs using salivary slgA. The Journal of Veterinary Medical Science/The Japanese Society of Veterinary Science, 67(7), 707-712. http://doi.org/10.1292/jvms.67.707

Kis, A., Hernádi, A., Kanizsár, O., Gácsi, M., \& Topál, J. (2015). Oxytocin induces positive expectations about ambivalent stimuli (cognitive bias) in dogs. Hormones and Behavior, 69, 1-7. http://doi.org/10.1016/j.yhbeh.2014.12.004

Kujala, M. V. (2017). Canine emotions as seen through human social cognition. Animal Sentience 14(1).

Kujala, M. V., Somppi, S., Jokela, M., Vainio, O., \& Parkkonen, L. (2017). Human empathy, personality and experience affect the emotion ratings of dog and human facial expressions. PLOS ONE, 12(1), 1-18. http://doi.org/10.1371/journal.pone.0170730

Maddock, R. J., Garrett, A. S., \& Buonocore, M. H. (2003). Posterior cingulate cortex activation by emotional words: fMRI evidence from a valence decision task. Human Brain Mapping, 18(1), 30-41. http://doi.org/10.1002/hbm.10075

McMillan, F. D. (2003). Maximising quality of life in ill animals. Journal of the American Animal Hospital Association, 39(3), 227-235.

Mendl, M., Brooks, J., Basse, C., Burman, O., Paul, E., Blackwell, E., \& Casey, R. (2010a). Dogs showing separation-related behaviour exhibit a "pessimistic" cognitive bias. Current Biology, 20(19). http://doi.org/10.1016/j.cub.2010.08.030

Mendl, M., Burman, O. H. P., \& Paul, E. S. (2010b). An integrative and functional framework for the study of animal emotion and mood. Proceedings. Biological Sciences/The Royal Society, 277(1696), 2895-904. http://doi.org/10.1098/rspb.2010.0303

Mendl, M., Burman, O. H. P., Parker, R. M. A., \& Paul, E. S. (2009). Cognitive bias as an indicator of animal emotion and welfare: Emerging evidence and underlying mechanisms. Applied Animal Behaviour Science, 118(3-4), 161-181.

http://doi.org/10.1016/j.applanim.2009.02.023

Mills, D. S. (2017). Perspectives on assessing the emotional behavior of animals with behavior problems. Current Opinion in Behavioral Sciences, 16, 66-72. http://doi.org/10.1016/j.cobeha.2017.04.002

Mills, D. S., \& Ewbank R. (2016). ISAE, ethology and the veterinary profession. In J. Brown, Y. Seddon, \& M. Appleby (Eds.), Animals and us: 50 years and more of applied ethology (pp. 966-981). Wageningen Academic Publishers.

Mills, D. S., Dube, M. B., \& Zulch, H. (2012). Stress and pheromonatherapy in small animal clinical behaviour. New York: John Wiley \& Sons, Inc.

Morton, D. (2007). A hypothetical strategy for the objective evaluation of animal well-being and quality of life using a dog model. Animal Welfare, 16(S1), 75-81.

Paul, E. S., Harding, E. J., \& Mendl, M. (2005). Measuring emotional processes in animals: The utility of a cognitive approach. Neuroscience and Biobehavioral Reviews, 29(3), 469-491. http://doi.org/10.1016/j.neubiorev.2005.01.002

Russell, J. A. (2003). Core affect and the psychological construction of emotions. Cognition and Emotion, 110(1), 145-172. http://doi.org/10.1080/02699930902809375

Sanders, C., Egger, M., Donovan, J., Tallon, D., \& Frankel, S. (1998). Reporting on quality of life in randomised controlled trials: bibliographic study. BMJ (Clinical Research Ed.), 317(7167), 1191-1194. 
Schwartz, C. E., \& Rapkin, B. D. (2004). Reconsidering the psychometrics of quality of life assessment in light of response shift and appraisal. Health and Quality of Life Outcomes, 2, 1-11. http://doi.org/10.1186/1477-7525-2-16

Travain, T., Colombo, E. S., Grandi, L. C., Heinzl, E., Pelosi, A., Prato Previde, E., \& Valsecchi, P. (2016). How good is this food? A study on dogs' emotional responses to a potentially pleasant event using infrared thermography. Physiology and Behavior, 159, 80-87. http://doi.org/10.1016/j.physbeh.2016.03.019

Travain, T., Colombo, E. S., Heinzl, E., Bellucci, D., Prato Previde, E., \& Valsecchi, P. (2015). Hot dogs: Thermography in the assessment of stress in dogs (Canis familiaris)-A pilot study. Journal of Veterinary Behavior: Clinical Applications and Research, 10(1), 17-23. http://doi.org/10.1016/j.jveb.2014.11.003

Wallis, L., Range, F., Huber, L., \& Wallis, L. J. (2017). Utilising dog-computer interactions to provide mental stimulation in dogs especially during ageing. Proceedings of the Fourth International Conference on Animal-Computer Interaction, 1, November. http://doi.org/10.1145/3152130.3152146

Yeates, J., \& Main, D. (2008). Assessment of positive welfare: A review. The Veterinary Journal, 175, 293-300.

Yeates, J., \& Main, D. (2009). Assessment of companion animal quality of life in veterinary practice and research. Journal of Small Animal Practice, 50(6), 274-281.

http://doi.org/10.1111/j.1748-5827.2009.00755.x 